\title{
Drug Resistance of Sea Lice Caligus rogercresseyi in Chile
}

\author{
Roberto Jaramillo $S^{*}$ \\ Doctoral Program in Sciences of Aquaculture, Chile \\ *Corresponding author: Roberto Jaramillo R, Proffesor, Institute of Marine and Limnological Sciences, Chile
}

Submission: 傮January 20, 2018; Published: 眥 February 05, 2018

\begin{abstract}
The sustained increase in salmonids production has leaded to the proliferation of caligidosis caused by the sea lice Caligus rogercresseyi. In order to reduce the effects of this ectoparasite, a series of products and methodologies has been tested. Emamectin benzoate, Azamethiphos and pyrethroids (Deltamethrin and Cypermethrin) immersion baths have been tested, unfortunately all of them caused resistance of the sea lice consequently resistance towards these drug treatments is rapidly growing in most salmon farming facilities in Chile. An alternative method controlling the caligidosis, the synchronization of treatments between neighboring farms, has been introduced.
\end{abstract}

\section{Introduction}

Aquaculture has become an important component of Chilean economy, mainly in the southern regions, where salmon farming is an active industry. Increase in salmonids production volumes, associated to high cultivation densities and close proximity between centers, has facilitated the development and expansion of caligidosis in the geographical areas where this activity takes place, contributing to both elevate the parasitic load and promoting the spread and prevalence of this epidemic [1,2]. Caligidosis in Chile, is caused by Caligus rogercresseyi [3], a native parasite of the rock cod (Cuvier) Eleginops maclovinus [4]. The life cycle of C. rogercresseyi includes eight developmental stages: two planktonic nauplii, an infective copepodite, four attached Chalimus stages and an adult stage, without pre-adult stages. Free living nauplii larvae are released from the paired egg strings attached to the adult female [5]. The literature suggests the parasite was transmitted from the native species to rainbow trout (Oncorhynchus mykiss W.) and Atlantic salmon (Salmo salar L.), because they are more susceptible to infection. However, in the last years, some juvenile stages of this parasite have also been found infecting smolts of Coho salmon (Oncorhynchus kisutch W.) after they have been transferred from freshwater [6].

In order to either, mitigate or eliminate the effects of this ectoparasite, a series of products and methodologies has been tested, including the use of disinfectants, antiparasitics, drugs, vaccines, natural products, predators, biocontrol fish, thermal baths, fresh water, ultrasound, electricity, optical laser, fences or skirts, baits, traps, etc. [7]. The literature indicates in Chile, between 2000 and 2007, the only treatment against C. rogercresseyi was the emamectin benzoate, which lost effectiveness after being used during that period (resistance); consequently, it was replaced by organophosphates applied by bath [8], followed by oral treatments $[2,9]$. Currently, the synthetic pyrethroids: deltamethrin and cypermethrin, are the most commonly used bath products for controlling C. Rogercresseyi which are administered topically through immersion treatments. However all these chemicals fail in controlling the infection, because immersion treatments do not produce a long lasting effect; so the anti-parasitic treatment inefficacy may be due: to low sensitivity of sea lice to drugs, inadequate drug administration procedures, and/or re-infestation from external sources of sea lice, such as infected neighboring farms [10].

Sea lice re-infestation from external sources can reduce the effectiveness of treatment by rapidly increasing the lice levels immediately post-treatment. Consequently resistance towards available drug treatments is rapidly growing in most salmon farming facilities in Chile; resistance mechanism include over expression of P-gps, CYPs, GST, carboxyl esterases, changes in glutamate- and histidine-gated ion channels and over expression of metabolic enzymes such as CYPs, GST, superoxide dismutase, mutations in the VDSC gene, and reduced cuticle penetration.

\section{Conclusion}

As a result of the increases in resistance of the salmon sea lice to the anti-parasitic drugs; synchronization of treatments (between neighboring farms) has been proposed as a strategy to improve immersion treatment performance [11]. Results indicate that synchronization was closely associated with lower adult lice levels from weeks 5 to 7 after treatment. This relationship appeared to be 
linear, suggesting that higher levels of synchronization may result in lower adult sea lice levels during these weeks. These findings suggest that synchronization between neighboring farms may improve the performance of immersion treatments by keeping sea lice levels low for a longer period of time [11].

However, using pesticides in marine waters can produce changes on microbial photo and chemoautotrophic carbon uptake. Although variable, these effects show significant alterations of carbon fixation fluxes if a single pesticide is applied as opposed to a combination of two or more compounds; i.e. Emamectin benzoate can potentially act as a depressor of carbon fixation while azamethiphos can stimulate primary production in conditions of nutrient limitation or deficiency. The effect of pesticides may be related to the magnitude of primary production and favorable conditions for phytoplankton activity [11].

\section{References}

1. Rozas M, Asencio G (2007) Assessment of Epidemiologic Situation of Caligiasis in Chile: Toward to Effective Control Strategy. Salmo Ciencia, pp. 43-59.

2. Bravo S, Sevatdal S, Horsberg T (2008) Sensitivity assessment of Caligus rogercresseyi to emamectin benzoate in Chile. Aquaculture 282: 7-12.

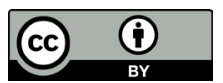

Creative Commons Attribution 4.0

International License

For possible submission use the below is the URL
3. Boxshall GA, Bravo S (2000) On the identity of the common Caligus (Copepoda:Siphonostomatoida: Caligidae) from salmonid netpen system in southern Chile. Contrib to Zool 69(1): 137-146.

4. Carvajal JL, González J, George NM (1998) Native sea lice (Copepoda: Caligidae) infestation of salmonids reared in netpen systems in southern Chile. Aquaculture 166(3-4): 241-246.

5. Bravo $S$ (2010) The reproductive output of sea lice Caligus rogercresseyi under controlled conditions. Exp Parasitol 125(1): 51-54.

6. González MT, Arenas B, Asencio G, Molinet C, Carvajal J (2012) Fecundity of sea louse Caligus rogercresseyi on native host Eleginops maclovinus, and farmed salmon in Southern Chile. Aquaculture Res 43: 853-860.

7. Asencio G (2014) La caligidosis, una parasitosis que complica a la salmonicultura chilena: Análisis de las estrategias de control actuales. Salmonexpert 8: 29-36.

8. Reyes X, Bravo S (1983) Nota sobre una copepoidosis en salmones de cultivo. Investigaciones Marinas. Valparaíso 11: 55-57.

9. Bravo S (2003) Sea lice in Chilean salmon farms. Bull Eur Ass Fish Pathol 23(4): 197-200.

10. Arriagada GA, Stryhn H, Campistó JL, Rees EF, Sanchez J, et al. (2014) Evaluation of the performance of pyrethroids on different life stages of Caligus rogercresseyi in southern Chile. Aquaculture 426/427: 231-237.

11. Arriagada G, Stryhn H, Sanchez J, Vanderstichel R, Campisto JL, et al. (2017) Evaluating the effect of synchronized sea lice treatments in Chile. Preventive Veterinary Medicine 136: 1-10.

\section{Your subsequent submission with Crimson Publishers will attain the below benefits}

- High-level peer review and editorial services

- Freely accessible online immediately upon publication

- Authors retain the copyright to their work

- Licensing it under a Creative Commons license

- Visibility through different online platforms

- Global attainment for your research

- Article availability in different formats (Pdf, E-pub, Full Text)

- Endless customer service

- Reasonable Membership services

- Reprints availability upon request

- One step article tracking system 